\title{
Recent micturition does not affect the detection of urethral gonorrhoea
}

\author{
FRANKLYN N. JUDSON, RICHARD A. WRIGHT, AND EDWARD A. MANN \\ From the Denver Metro Health Clinic, Denver Health and Hospitals, 605 Bannock Street, Denver, Colorado
}

SUMMARY In 202 men with urethral gonorrhoea (176 symptomatic and 26 asymptomatic) who had modified Thayer-Martin cultures taken before and within five minutes after micturition there was complete agreement between results of the two cultures. Micturition did, however, temporarily eliminate the discharge in $100(56.8 \%)$ and make interpretation of Gram-stained smears more laborious.

\section{Introduction}

It has been suggested that men who suspect they have gonorrhoea should not micturate for a period of time before urethral specimens for cultures and/or Gram stains are collected. A minimum period of time has never been determined and in many clinics patients are merely advised to avoid micturating until the examination and investigation are completed. However, there is no evidence that micturition washes away enough gonococci to give false negative results to modified Thayer-Martin (MTM) (Center for Disease Control, 1974) culture or Gramstained smear.

We, therefore, studied the effect of micturition on the quantity and quality of the urethral discharge, and on the detection of urethral gonococci by both MTM medium and Gram-staining techniques.

\section{Materials and methods}

SYMPTOMATIC URETHRAL GONORRHOEA From 22 July to 6 October 1976, 176 men $(45.5 \%$ White, $42 \cdot 6 \%$ Black, $11.9 \%$ Hispano) with Gramstain positive urethral discharges were enrolled in the study.

The quantity of discharge was estimated by the clinician as:

Profuse -discharge dripping spontaneously from the urethral meatus

Moderate-meatal discharge readily apparent on

\footnotetext{
Address for reprints: Dr F. N. Judson, Director, Disease Contro Service, Denver Health and Hospitals, 605 Bannock Street, Denver CO 80204, USA

Received for publication 30 March 1977
}

physical inspection but not dripping spontaneously

Scanty - meatal discharge only visible after urethral massage.

The quality was also noted as purulent, white, or clear. An intraurethral calcium-alginate swab specimen (U-1) was then inserted $1-2 \mathrm{~cm}$ into the urethra and immediately streaked on MTM medium. The patient was asked when he had last passed urine and then was requested to void completely into the lavatory. In the case of the last 51 patients the volume of urine was measured. Within five minutes of voiding, the clinician again estimated the quantity and quality of any remaining discharge and took a second urethral swab (U-2) in the same manner as the first. A Gram stain was then taken on each of the last 51 patients by passing a slide over the external meatus. This Gram stain was read by a different technician from the one who read the initial one. Reading was limited to three minutes a slide, and results were confirmed by a second technician.

MTM medium was immediately placed in an incubator at $36^{\circ} \mathrm{C}$ containing 5 to $10 \%$ carbon dioxide. Isolates were identified after 48 hours' incubation by oxidase reaction and Gram stain.

ASYMPTOMATIC URETHRAL GONORRHOEA Twenty-six men returning for treatment of asymptomatic urethral gonorrhoea found by culture taken two or three days earlier still reported no dysuria or discharge and had no discharge on genital examination, even after urethral massage. The procedure described above was repeated for these men, except that no estimation of quantity and quality of discharge could be made and no smears for Gram staining were taken. 


\section{Results}

SYMPTOMATIC URETHRAL GONORRHOEA

The median duration of discharge was two days (range: 4 hours to 21 days) and the median time from last micturition to the initial genital examination was 2 hours (range: 15 minutes to 16 hours). For the last 51 patients, the mean urine volume was $122 \cdot 1 \mathrm{ml}$ (range: 25 to $350 \mathrm{ml}$ ). Table 1 presents the

Table 1 Characteristics of gonococcal urethral exudates in 176 men before and after micturition

\begin{tabular}{|c|c|c|c|c|}
\hline \multirow{2}{*}{$\begin{array}{l}\text { Quantity and quality } \\
\text { of discharge }\end{array}$} & \multicolumn{2}{|c|}{ Before micturition } & \multicolumn{2}{|c|}{ After micturition } \\
\hline & No. & $\%$ & No. & $\%$ \\
\hline Profuse purulent & 71 & $40 \cdot 3$ & 1 & 0.6 \\
\hline Moderate purulent & 48 & $27 \cdot 3$ & 6 & $3 \cdot 4$ \\
\hline Scant purulent & 14 & $8 \cdot 0$ & 6 & $3 \cdot 4$ \\
\hline Profuse white & 5 & $2 \cdot 8$ & 8 & $4 \cdot 6$ \\
\hline Moderate white & 17 & $9 \cdot 7$ & 25 & $14 \cdot 2$ \\
\hline Scant white & 12 & $6 \cdot 8$ & 21 & $11 \cdot 9$ \\
\hline Profuse clear & 2 & $1 \cdot 1$ & 0 & 0.0 \\
\hline Moderate clear & 3 & $1 \cdot 7$ & 3 & $1 \cdot 7$ \\
\hline Scant clear & 4 & $2 \cdot 3$ & 6 & $3 \cdot 4$ \\
\hline No discharge & 0 & 0.0 & 100 & $56 \cdot 8$ \\
\hline
\end{tabular}

effect that complete voiding had on the quantity and quality of 176 urethral discharges which were reevaluated within five minutes. Table 2 shows that there was agreement between the results of cultures taken before and after micturition. Of 51 Gram stains taken after micturition, 47 still revealed typical intracellular Gram-negative diplococci, while four contained only extracellular Gram-negative diplococci.

ASYMPTOMATIC URETHRAL GONORRHOEA In the 26 men with asymptomatic infection, complete agreement between results of pre- and postmicturition cultures was again obtained (Table 2).

Table 2 Agreement between urethral cultures taken before and after micturition

\begin{tabular}{|c|c|c|c|c|}
\hline \multirow[t]{2}{*}{$\begin{array}{l}\text { Type of urethral } \\
\text { gonorrhoea }\end{array}$} & \multicolumn{2}{|c|}{$\begin{array}{l}U-1 \text { Positive/U-2 } \\
\text { Positive }\end{array}$} & \multicolumn{2}{|c|}{$\begin{array}{l}U-1 \text { Negative/U-2 } \\
\text { Negative }\end{array}$} \\
\hline & No. & $\%$ & No. & $\%$ \\
\hline $\begin{array}{l}\text { Gram stain positi } \\
\text { Symptomatic } \\
(N=176)\end{array}$ & 168 & $(95 \cdot 5)$ & 8 & $(4 \cdot 5)$ \\
\hline $\begin{array}{l}\text { Asymptomatic } \\
(N=26)\end{array}$ & 15 & $(57 \cdot 7)$ & 11 & $(42 \cdot 3)$ \\
\hline
\end{tabular}

\section{Comment}

The control of gonorrhoea depends to a large extent on the sensitivity of available diagnostic tests-that is, our ability to detect infection when present and to exclude it when absent. It is, therefore, important to know if normal micturition washes away enough gonococci and neutrophils temporarily to eliminate the discharge and to give false negative results to cultures and Gram-stained smears of urethral exudates.

Micturition had the expected clearing effect on discharges (Table 1). Thus, $67.7 \%$ of pre-urination discharges but only $4.0 \%$ of post-urination discharges were described as moderate or profuse/ purulent. No discernible discharge remained in $56.8 \%$, but it may be assumed that urethral discharges regenerate rapidly since the median time reported between micturition before attending the clinic and the initial examination was just two hours.

Cultures taken within five minutes of voiding should show the maximum effect of micturition on the detection of urethral gonococci. None the less, we found complete agreement between pre- and postvoiding MTM cultures in both symptomatic and asymptomatic infection, indicating that this technique is sufficiently sensitive to detect the smaller numbers of gonococci which are left behind.

The sensitivity of MTM medium has never been one hundred per cent (Schmale et al., 1969; Dans and Judson, 1975), so it is not surprising that in eight of 176 patients in whom exudates revealed typical intracellular Gram-negative diplococci, no gonococci were recovered from either pre- or post-voiding MTM cultures. There are several potential factors affecting this insensitivity. Firstly, gonococci seen in Gram stains may not be viable as a result of self-medication or the development of an effective immune response; secondly, MTM medium in general (Dars ard Judson, 1975), and the vancomycin component in particular (Cross et al., 1971; Bronson et al., 1973), may be toxic to certain gonococcal strains. Thirdly, the inoculum of viable gonococci from both pre- and post-voiding specimens may occasionally be too small. The first and third factors may explain the negative MTM cultures in the 11 asymptomatic patients who were known to have had positive urethral cultures taken at a visit to the clinic three to seven days earlier.

Post-voiding Gram stains of direct external meatal smears were certainly more difficult to interpret than initial smears. The stained material was often diluted with urine. Despite this, our technicians were able to identify typical intracellular Gram-negative diplococci on 47 of 51 post-voiding smears.

Physicians should be aware that micturition can clear a gonococcal urethral discharge for a short period of time and can make the accurate interpretation of a meatal Gram-stained smear more difficult. It should not, however, impair the ability of a well performed MTM culture to detect gonorrhoea. 
Dr Richard Rothenberg suggested this study. The conscientious work of the Denver Metro Health Clinic clinicians is gratefully acknowledged as is the secretarial assistance of Ms Fern Lemaster and Ms Katie Andersen.

\section{References}

Bronson, J. E., Holmberg, I., Nygrem, B., and Seeberg, S. (1973). Vancomycin-sensitive strains of Neisseria gonorrhoea. A problem for the diagnostic laboratory. British Journal of Venereal Diseases, $49,452-453$.

Center for Disease Control (1974). Criteria and Techniques for the Diagnosis of Gonorrhea. Center for Disease Control: Atlanta.

Cross, R. C., Hoger, M. D., Neibaur, B. A., Pasternack, B., and Brady, F. (1971). VCN-inhibited strains of Neisseria gonorrhoeae. Health Services and Mental Health Administration Health Reports, 86, 990-992.

Dans, P. E., and Judson, F. N. (1975). The establishment of a venereal disease clinic. II. An appraisal of current diagnostic methods in uncomplicated urogenital and rectal gonorrhea. Journal of the American Venereal Disease Association, 1, 107-112.

Schmale, J. D., Martin, J. E. Jr, and Domescik, G. (1969). Observations on the culture diagnosis of gonorrhea in women. Journal of the American Medical Association, 210, 312-314. 